\title{
THE BENCHMARK ACTIVE CONTROLS TECHNOLOGY MODEL AERODYNAMIC DATA
}

\author{
Robert C. Scott ${ }^{*}$, Sherwood T. Hoadley ${ }^{\dagger}$, Carol D. Wieseman ${ }^{\ddagger}$, and Michael H. Durham ${ }^{\S}$ \\ NASA Langley Research Center \\ Hampton, VA
}

\begin{abstract}
The Benchmark Active Controls Technology (BACT) model is a part of the Benchmark Models Program (BMP). The BMP is a NASA Langley Research Center program that includes a series of models which were used to study different aeroelastic phenomena and to validate computational fluid dynamics codes. The primary objective of BACT testing was to obtain steady and unsteady loads, accelerations, and aerodynamic pressures due to control surface activity in order to calibrate unsteady CFD codes and active control design tools. Three wind-tunnel tests in the Transonic Dynamics Tunnel (TDT) have been completed. The first and parts of the second and third tests focused on collecting open-loop data to define the model's aeroservoelastic characteristics, including the flutter boundary across the Mach range. It is this data that is being presented in this paper. An extensive database of over 3000 data sets was obtained. This database includes steady and unsteady control surface effectiveness data, including pressure distributions, control surface hinge moments, and overall model loads due to deflections of a trailing edge control surface and upper and lower surface spoilers.
\end{abstract}

\section{SYMBOLS}

$\begin{array}{ll}\alpha & \text { angle of attack, alpha } \\ \mathrm{b} & \text { model span (32 in.) } \\ \mathrm{c} & \text { model reference chord (16 in.) } \\ \mathrm{C}_{\mathrm{L}} & \text { lift coefficient }=\text { lift/qS } \\ \mathrm{C}_{\mathrm{M}} & \text { pitching moment coefficient }= \\ & \text { pitching moment/qSc } \\ \mathrm{C}_{\mathrm{P}} & \text { pressure coefficient }=\left(\mathrm{P}-\mathrm{P}_{\infty}\right) / \mathrm{q}\end{array}$

*Aeroelasticity Branch, Aerospace Engineer, Member AIAA

${ }^{\dagger}$ Aeroelasticity Branch, Senior Aerospace Engineer, Associate Member AIAA

${ }^{\ddagger}$ Aeroelasticity Branch, Aerospace Engineer, Senior Member AIAA

${ }^{\S}$ Subsonic Transportation Office, Aerospace Engineer, Senior Member AIAA

Copyright (C) 1997 by the American Institute of Aeronautics and Aeronautics, Inc. No copyright is asserted in the United States under Title 17, U.S. Code. The U.S. Government has a royalty-free license to exercise all rights under the copy right claimed herein for government purposes. All other rights are reserved by the copyright owner.

$\begin{array}{ll}\mathrm{C}_{1} & \begin{array}{l}\text { rolling moment coefficient }=\text { rolling } \\ \text { moment/qSb } \\ \text { deflection of control surface }\end{array} \\ \delta & \text { Mach number } \\ \mathrm{M} & \text { pressure } \\ \mathrm{P} & \text { free stream pressure } \\ \mathrm{P}_{\infty} & \text { dynamic pressure }\left(1 / 2 \rho \mathrm{V}^{2}\right) \\ \mathrm{q} & \text { density } \\ \rho & \text { reference area }=\mathrm{bc} \\ \mathrm{S} & \text { velocity } \\ \mathrm{V} & \text { non-dimensional chord location } \\ \mathrm{x} / \mathrm{c} & \end{array}$

\section{NOMENCLATURE}

CS channel statistics data and tables

dwell oscillation at a fixed frequency

LinSS linear sine sweep

LS lower spoiler

MILEA model inboard leading edge accelerometer

MITEA model inboard trailing edge accelerometer

MOLEA model outboard leading edge accelerometer

MOTEA model outboard trailing edge accelerometer

MP magnitude and phase data and tables

polar variation of a single parameter such as $\alpha$,

$\delta_{\mathrm{TE}}, \delta_{\mathrm{US}}, \delta_{\mathrm{LS}}$

PPN periodic pseudo-noise excitation

TE trailing edge control surface

$\mathrm{TF}$ transfer functions

$\mathrm{TH}$ time history data

US upper spoiler

US+LS motion of upper and lower spoilers are in same direction

US-LS motion of spoilers are in opposing directions

\section{INTRODUCTION}

Some of the interesting aeroelastic phenomena existing in today's aircraft include the following: the classical transonic flutter "bucket", wing/store limited amplitude flutter, shock induced instabilities, and dynamic vortex-structure interactions. Transonic aeroelastic phenomena are often very difficult to understand and analyze. With the rapid increase in computation speeds, new computational fluid dynamic (CFD) codes have matured sufficiently to 
analyze some of these unsteady transonic phenomena. As these new CFD codes are applied to more complex configurations, a need exists for more experimental data from well-defined and documented configurations in order to better test and evaluate the analytical results.

The Structures Division of NASA Langley Research Center (LaRC) initiated the Benchmark Models Program (BMP) ${ }^{1}$. The goal of the BMP was to obtain experimental data for validating unsteady CFD codes. This program included a series of five models of varying complexity. All the models have the same planform, but four different airfoil shapes were used. Figure 1 shows a list of the five models and when they were tested.

\begin{tabular}{|c|c|c|c|c|c|c|c|}
\hline & 1990 & 1991 & 1992 & \begin{tabular}{|l}
1993 \\
\end{tabular} & 1994 & 1995 & $\begin{array}{l}1996 \\
119\end{array}$ \\
\hline Circular Arc & I I & & & & & & \\
\hline NACA 0012 & I & & & & & & \\
\hline NASA SC(3)-0414 & & & & & & & \\
\hline NACA $64 A 010$ & & & & & I & & \\
\hline BACT (NACA 0012) & & & & I & & & I \\
\hline
\end{tabular}

Figure 1.- Benchmark models program wind tunnel tests.

The Benchmark Active Controls Technology (BACT) model is one of the models defined in the Benchmark Models Program. The primary goal of this benchmark active controls project was to further expand the experimental database for validating unsteady CFD codes to include a trailing edge control surface and spoilers. Secondary goals were to 1) validate active controls analytical tools, including plant estimation and controller performance evaluation, and 2) provide an active controls testbed for evaluating new control methodologies. This model has the NACA 0012 airfoil shape. The data acquired during the testing of the BACT model extended the unsteady pressure data base and the documented stall and flutter instabilities of the previously tested NACA 0012 model.

As indicated in Figure 1, three tests of this model have been completed. The objective of the first test was to create an extensive data base of pressures, loads, and transfer functions for the open-loop model. In the following two tests the model was primarily used as an active controls testbed, however, some open-loop data were also acquired during these tests. During the three wind-tunnel tests an extensive database of over 3000 data sets was obtained. This database includes steady and unsteady control surface effectiveness (i.e. pressure distributions and overall model loads) due to static and dynamic deflections of a trailing edge control surface and upper and lower surface spoilers. The control surfaces were tested with static displacements, sinusoidal oscillations, sine sweeps, and periodic pseudo-noise. The surfaces were tested individually and in combinations with spoilers oscillating both in and out of phase. The purpose of this paper is to describe the model and summarize this database.

\section{TESTING APPARATUS}

\section{Model}

The BACT model is similar in geometry, airfoil section shape, and instrumentation to the previously tested NACA 0012 model presented in reference 1. A photograph of the BACT model is shown in Figure 2. This figure also includes model dimensions and locations of accelerometers. The active controls model extends the unsteady pressure data base and the documented flutter instabilities of the NACA 0012 model. Both rigid models have a rectangular wing with a reference chord of 16 inches and a span of 32 inches, thus a semispan aspect ratio of 2 , and a reference area of $512 \mathrm{in}^{2}$. On the BACT model, a trailing edge control surface and a pair of independently actuated upper and lower surface spoilers have been added. The span of all three control surfaces is 30 percent of the model span, centered about the model 60 percent span station. The trailing-edge control surface width is 25 percent of the model chord. Both spoiler widths are 15 percent of the model chord and hinged at the 60 percent chord station. All three control surfaces are moved with independent miniature hydraulic actuators. The actuators allow static control surface displacements or dynamic control surface oscillations about a mean angle. The trailing edge control surface deflection is mechanically limited to 15 degrees either up or down. Each spoiler may be deployed from a 0 degrees, stowed position, to any angle up to 45 degrees. During testing, a transition strip was installed on the model at approximately the $5 \%$ chord station on both the upper and lower surfaces.

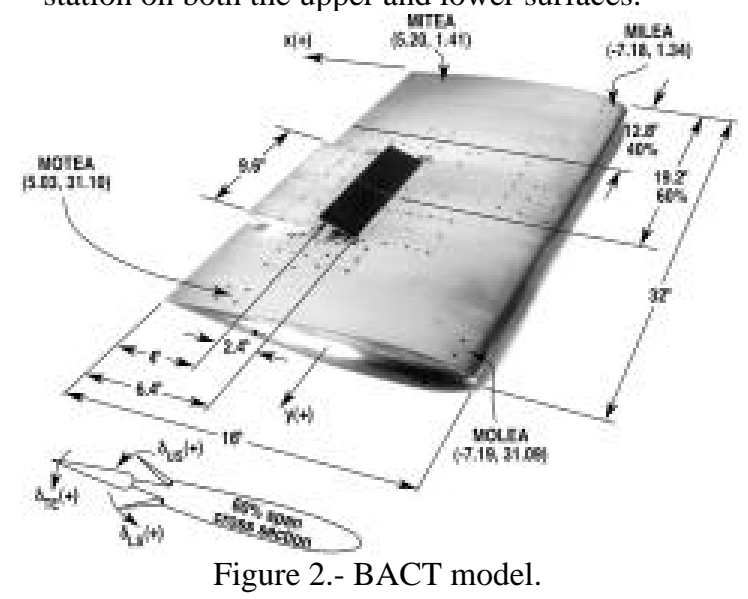


The combination of a height restriction of one inch due to model cavity thickness, the torque requirements of oscillating instrumented control surfaces at high frequencies, and maximum spoiler displacements of up to 45 degrees warranted the development of specially designed actuators for both the trailing edge control surface and the spoilers. A rotary vane actuator was developed for the trailing edge control surface. The breadboard version of this actuator is shown in reference 2. A miniature tandem set of piston actuators was developed for the spoilers. Reference 3 presents the experimental transfer functions for each of the three actuators, assesses the effects of wear and aerodynamic loading, and develops analytical models for each actuator.

\section{Mount Systems}

The mount systems used to support the BACT model consisted of either a rigid or a flexible support and a large splitter plate. Figure 3 shows the BACT model attached to each of the supports, and Figure 4 shows the model, support, and splitter plate mounted in the wind tunnel. Note that the support is contained in the aerodynamic fairing behind the splitter plate.

The rigid support was only used in the first half of testing during the 1993 test of the BACT model. It consisted of a rigid strut attached to the tunnel sidewall turntable and a five degree-of-freedom balance. Five forces were measured with the balance: normal, drag, pitching moment, rolling moment, and yawing moment. For BACT testing, lift was positive up, drag was positive aft, pitching moment was positive leading edge up, and rolling moment was positive tip up.

The flexible support allows for the investigation of aeroelastic instabilities. The Pitch and Plunge Apparatus (PAPA) mount system ${ }^{4}$ was developed at LaRC and provides the two flexible degrees of freedom needed for classical flutter. The PAPA consists of a fixed plate attached to the tunnel sidewall turntable, a set of four fixed-end rods, a rectangular shaped drag strut, and a moving plate. The mount system can be dynamically tuned by the addition of masses attached to the moving plate to adjust the model center of gravity and the frequencies of vibration. The center of gravity is located at the model mid-chord to provide uncoupled wind-off pitch

Table 1.- Measured structural dynamic parameters.

$\begin{array}{lll} & \text { Plunge Mode } & \text { Pitch Mode } \\ & & \\ \text { Frequency } & 3.34 \mathrm{~Hz} . & 5.21 \mathrm{~Hz} . \\ \text { Stiffness } & 2,686 \mathrm{lb} / \mathrm{ft} & 3,000 \mathrm{ft}-\mathrm{lb} / \mathrm{rad} \\ \text { Damping Ratio } & 0.0014 & 0.0010 \\ \text { Generalized Mass } & 6.08 \mathrm{Slug} & 2.80 \mathrm{Slug}-\mathrm{ft}^{2}\end{array}$

and plunge degrees of freedom. The rigid-body plunge mode consists only of vertical translation of the wing model and the rigid-body pitch mode only of rotation of the wing model about the mid-chord. The measured structural dynamic parameters are shown in Table 1. The PAPA mount system allows a model angle of attack up to 6 degrees, static loads up to 325 lb., and displacements of 1.5 inches either up or down.

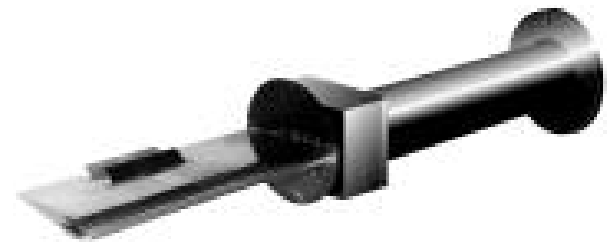

a) BACT model on the rigid mount (balance and strut).

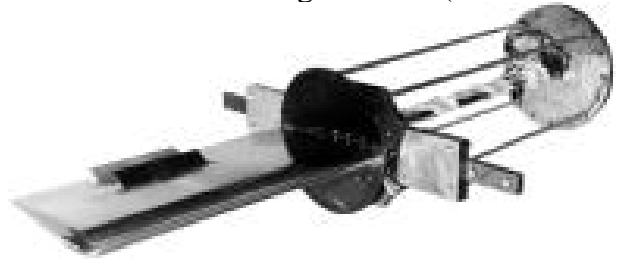

b) BACT model on the flexible mount (PAPA).

Figure 3.- BACT model on rigid and flexible mount systems.

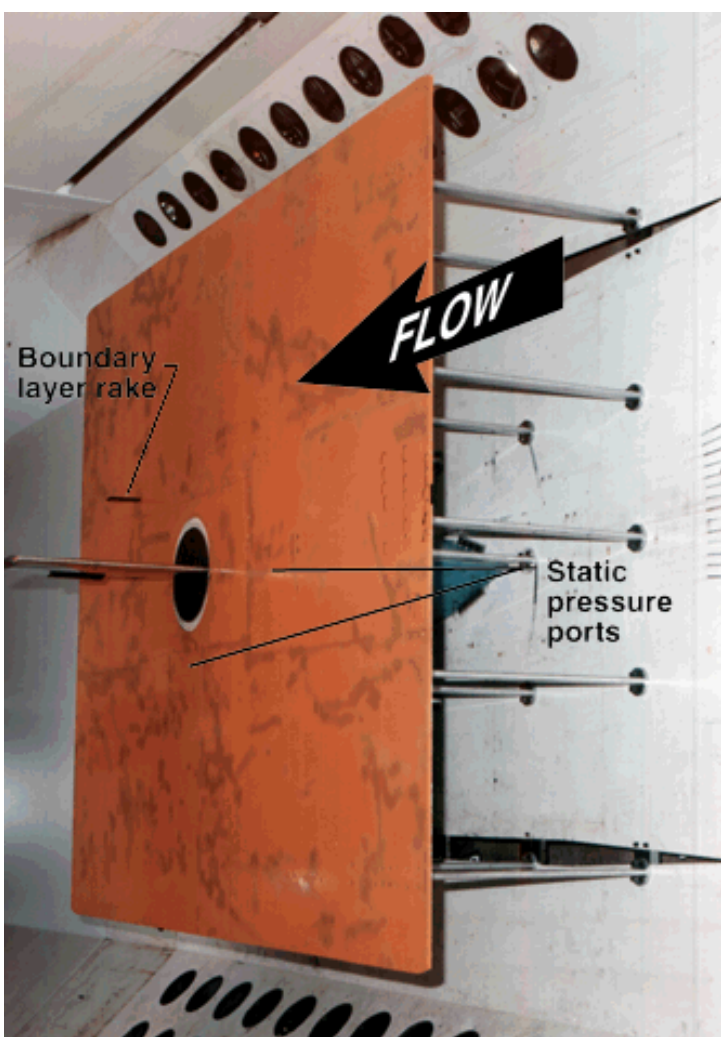

Figure 4.- BACT model installed in Transonic Dynamics Tunnel. 


\section{Instrumentation}

The BACT model instrumentation is designed to obtain unsteady pressure distributions during sustained model oscillations up to and including flutter onset. Differential pressure transducers were installed at two span stations on the model. These differential transducers were referenced to the tunnel static pressure. Refer again to Figure 2. The pressure orifice distribution at the 60 percent span station is similar to the NACA 0012 model. Additional transducers have been included in the area of the three control surface hinge lines. A total of 58 pressure transducers are installed at this span station. An additional partial chord of 17 transducers were installed inboard of the three control surfaces, at the 40 percent span station. Figure 5 shows the chordwise locations of the pressure orifices at the 40

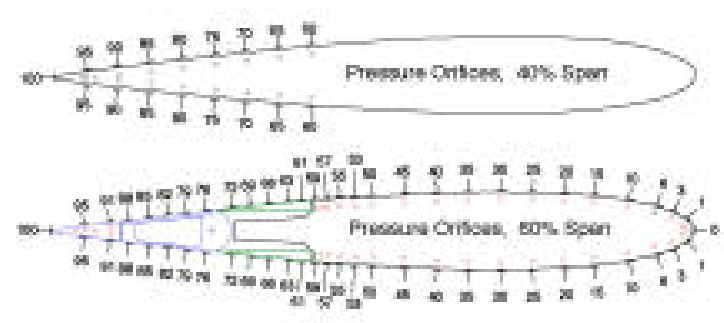

Figure 5.- BACT model orifice locations.

and 60 percent span locations. An additional 20 insitu pressure transducers are mounted in the splitter plate to measure the aerodynamic boundary conditions. A boundary layer rake with 10 probes is mounted off the splitter plate, aft and slightly above the model, to record the thickness of the wall boundary layer. These can be seen in Figure 4 . Model accelerometers are located near the four corners of the wing to measure the pitch and plunge accelerations and to verify that no local model vibration modes are present in the frequency range of interest; i.e. to assure that the model itself remains rigid with only the two degrees of freedom resulting from the PAPA. Potentiometers were used to measure the three control surface deflections. Two

Table 2.- Instrumentation.

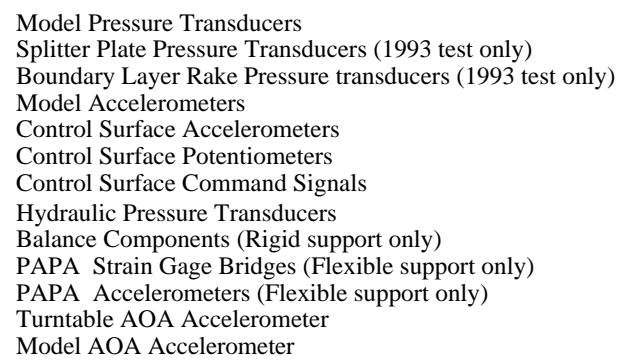

138 Signals pressure transducers per control surface actuator were used to measure the differential hydraulic pressure across the actuator. Table 2 lists the instrumentation used during the tests.

\section{Wind Tunnel}

Wind-tunnel testing was conducted in the NASA Langley Transonic Dynamics Tunnel (TDT) ${ }^{5}$. The TDT is a closed circuit, continuous flow, variabledensity, transonic wind tunnel. The slotted test section is $16 \mathrm{ft}$ by $16 \mathrm{ft}$ square with cropped corners. The speed and pressure are independently controllable over a range of Mach numbers from 0.0 to 1.2 (unblocked), and a range of stagnation pressures from near zero to one atmosphere. Either air or a heavy gas can be used as the test medium. For the BACT tests, both air and R-12 were used. The TDT is also equipped with quick-opening bypass valves which can be activated to rapidly reduce test-section dynamic pressure and Mach number when flutter occurs. The combinations of large scale, high speed, heavy gas, variable pressure, and the bypass-valve system make the TDT ideally suited for aeroelastic testing.

\section{DATA ACQUISITION AND REDUCTION}

Wing model and mount system sensor time history data (accelerations, loads, and pressures) were acquired at the conditions described in the next section of the paper. In all cases, the data were acquired simultaneously, using sample and hold, for all sensor signals at a rate of 500 samples/second on the primary TDT Data Acquisition System and recorded in digital form on a disk. Records from 10 to 30 seconds duration were recorded, depending on the test condition. A subset of the acceleration and load signals were also acquired on a secondary system at 200 samples/second, sampled sequentially, but for longer durations.

For all conditions, steady and unsteady, the following channel statistics (CS): means, minimums, maximums and standard deviations, were calculated for all analog signals and for pressure coefficients at all locations on the wing. These channel statistics were saved in ASCII files for general use. Tables and plots of the pressure coefficients were also generated and saved for publication and general use using EXCEL $^{\circledR}$ spreadsheet macros and templates. All pressure data were corrected by first applying windoff-zero (wind-off, zero dynamic pressure) corrections. The balance loads were calculated by removing interactions between the balance signals and recorded for each test condition. Only the uncorrected balance signals, not the corrected balance loads, are available as time histories. 
For unsteady data due to an aeroelastic instability, such as flutter, or in response to oscillating control surfaces at a specific frequency, magnitude and phase (MP) with respect to a reference channel at the frequency of interest were also calculated. Once again, tables and plots of magnitude and phase were also generated and saved for publication and general use.

For unsteady data due to oscillating control surfaces with sweeps or periodic pseudo-noise, transfer functions of model response with respect to the control surface motion and actuator transfer functions were calculated using MATLAB ${ }^{\circledR}$. These transfer functions were plotted and saved on binary files for future reference and documentation. The periodic pseudo-noise ${ }^{6}$ was a specially designed excitation that provided high signal-to-noise ratios with a frequency content specified by the engineer and subject to constraints on control surface rates. It is not truly random. The specific frequency content is based on the frequency resolution, determined by the block size and the nyquist frequency, and the frequency band of interest.

The raw time history (TH) data are saved in counts along with all engineering unit (EU) conversion information. An interface program, written in $\mathrm{C}$, was developed by NASA to convert the TH data to various ASCII and binary formats, including MATLAB ${ }^{\circledR}$ binary format. A MATLAB-based TDT analysis package was also developed at NASA to convert the data to EU's and perform a multitude of specific analysis options. This TDT analysis package is also able to process and generate the CS and MP data files required by the EXCEL ${ }^{\circledR}$ templates mentioned above. Documentation and procedures are available upon request to convert the data and perform any of the post test analysis options discussed herein. Depending on the type of testing, TH, CS, MP, and TF data are available.

\section{EXPERIMENTAL RESULTS}

This section of the paper will describe the data base of experimental results. The discussion is divided into two parts. The first part describes data obtained on the rigid mount and the second part describes data obtained on the flexible mount. In each case, tables summarizing the available data sets will be discussed and example plots will be shown. The test medium for all the following data was a heavy gas, R-12.

\section{Rigid Mount}

Data were acquired on the rigid mount for a series of different model angles of attack, with control surfaces having various static displacements, sinusoidal oscillation, linear sine sweeps, and periodic-pseudonoise inputs. The steady and unsteady rigid data sets are summarized in Table 3 and Table 4, respectively.

The tunnel conditions, model angle of attack, and control surface bias combinations where steady data were acquired are summarized in Table 3 . This table is sorted by polar type and Mach number. The polar type identifies the particular parameter that is being varied. These data can best be viewed by looking at plots of the mean loads and mean pressures. Figure 6 shows the lift, pitching moment, and rolling moment coefficients as functions of angle of attack for the Mach 0.77 alpha polar. As can be seen, all increase with increasing alpha. The drag polar plot, displaying lift versus drag, corresponding to this same tunnel condition for varying alpha is shown in Figure 7, and the mean pressures for both the upper and lower model surfaces for alpha varying between

Table 3.- Rigid polar data.

\begin{tabular}{|c|c|c|c|c|c|c|c|}
\hline \multirow[b]{2}{*}{ M } & \multirow[b]{2}{*}{$q(p s f)$} & \multirow{2}{*}{$\begin{array}{l}\text { Polar } \\
\text { Type }\end{array}$} & \multirow[b]{2}{*}{ Polar Values (Degrees) } & \multirow[b]{2}{*}{ Alpha (Degrees) } & \multicolumn{3}{|c|}{ Biases (Degrees) } \\
\hline & & & & & TE & US & LS \\
\hline 0.5 & 93 & Alpha & $0,1,2,4,6,8,10,12$ & - & 0 & 0 & 0 \\
\hline 0.65 & 145 & Alpha & $-4,-2,0,0.5,1,2,4,6$ & - & 0,5 & 0 & 0 \\
\hline 0.75 & 156 & Alpha & $-4,-2,0,0.5,1,2,3,4,5,6,7,8$ & - & 0 & 0 & 0 \\
\hline 0.77 & 141 & Alpha & $-4,-2,0, .5,1,2,3,4,5,6,7,8,9$ & - & 0 & 0 & 0 \\
\hline 0.77 & 143 & Alpha & $-4,-2,0, .5,1,2,3,4,5,6,7,8$ & - & -5 & $0,-20,-40$ & 0,20 \\
\hline 0.82 & 169 & Alpha & $-4,-2,0, .5,1,2,3,4,5,6,7,8,9,10$ & - & 0 & 0 & 0 \\
\hline 0.82 & 173 & Alpha & $-4,-2,0,0.5,1,2,4$ & - & 5 & 0 & 0 \\
\hline 0.82 & 173 & Alpha & $-4,-2,0,0.5,1,2,4$ & - & 0 & -20 & 0 \\
\hline 0.82 & 173 & Alpha & $-4,-2,0,0.5,1,2,4$ & - & 0 & 0 & 20 \\
\hline 0.9 & 135 & Alpha & $0, .3, .5, .8,1,1.5,2,3$ & - & 0,2 & 0 & 0 \\
\hline 0.5 & 93 & TE & $-4,-2,0,0.5,1,2,4,6$ & 0 & - & 0 & 0 \\
\hline 0.65 & 145 & TE & $-10,-5,-2,0,2,5,10$ & $0,2,4$ & - & 0 & 0 \\
\hline 0.75 & 156 & TE & $-10,-5,-2,0,1,2,3,5,10,12$ & $0,2,4$ & - & 0 & 0 \\
\hline 0.77 & 145 & TE & $-10,-5,-2,0, .5,1,2,3,5,10,12$ & $0,1,2,4,5,6,8$ & - & 0 & 0 \\
\hline 0.82 & 171 & TE & $-10,-5,-2,0, .5,1,2,3,5,10,12$ & $0,2,4$ & - & 0 & 0 \\
\hline 0.9 & 135 & TE & $-5,-2,-1,-.5,0, .5,1,1.5,2,5$ & $0, .5,1$ & - & 0 & 0 \\
\hline 0.65 & 145 & US & $0,-5,-10,-20,-40$ & 0,4 & 0 & - & 0 \\
\hline 0.77 & 150 & US & $0,-0.5,-1,-2,-5,-10,-15-20,-25,-35,-43$ & $-2,0,2,4,5,6,8$ & 0 & - & 0 \\
\hline 0.77 & 150 & US & $0,-0.5,-1,-2,-5,-10,-15-20,-25,-35,-43$ & $-2,0,2,4,5,6,8$ & 0 & - & $0,5,10$ \\
\hline 0.77 & 150 & US & $-5,-10,-20$ & $-2,0,2,5$ & $5,10,12$ & - & 0 \\
\hline 0.82 & 171 & US & $0,-1,-2,-5,-10,-15,-20,-43$ & $0,2,4$ & $5,10,12$ & - & 0,5 \\
\hline 0.9 & 138 & US & $0,-1,-2,-3$ & $0,0.5$ & 0 & - & 0 \\
\hline
\end{tabular}


-4 and 8 degrees is shown in Figure 8. Two key features of this last plot are that for angles greater than 2 degrees in magnitude, a shock develops on one of the wing surfaces and the dip in the pressures near the leading edge is caused by the presence of the transition strip. An upper spoiler polar and a trailing edge control surface polar are shown in Figure 9 and Figure 10, respectively. Both plots are for $\alpha=5$ degrees so that the control surface effect on the shock could be demonstrated. The loads due to trailing edge control surface deflection and upper spoiler deflection

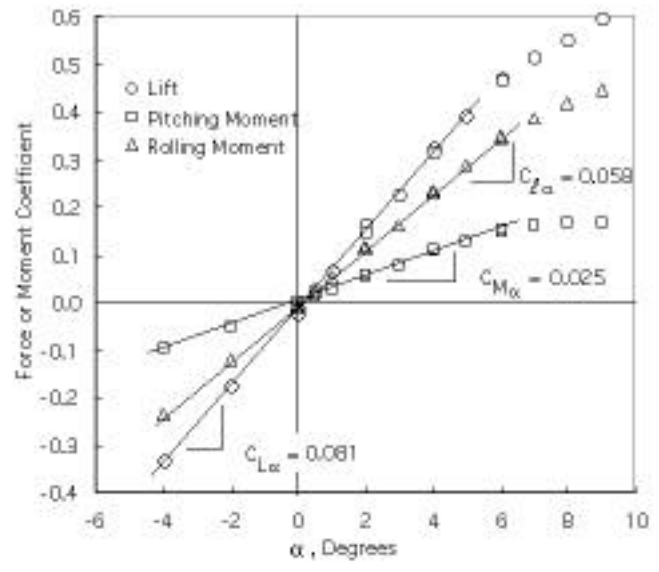

Figure 6.- Force and moment coefficients as a function of alpha, $\mathrm{M}=0.77$ and $\mathrm{q}=141.5 \mathrm{psf}$.

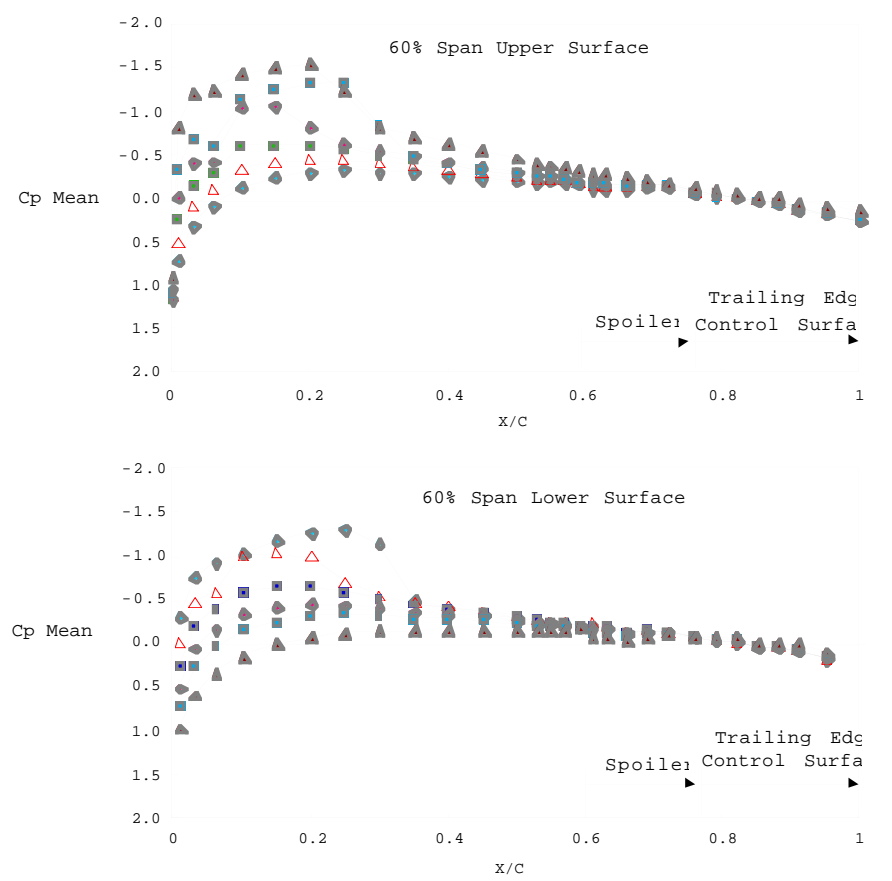

are shown in Figure 11 and Figure 12, respectively. As can be seen, lift and rolling moment increase with increasing deflection. In the case of the upper spoilers, this implies that lift and rolling moment increase as the spoiler goes from fully deployed to stowed. The relationship between load and deflection is fairly linear for the trailing edge control surface and nonlinear for upper spoiler. The pitching moment is not greatly affected by changes in deflection of either control surface.

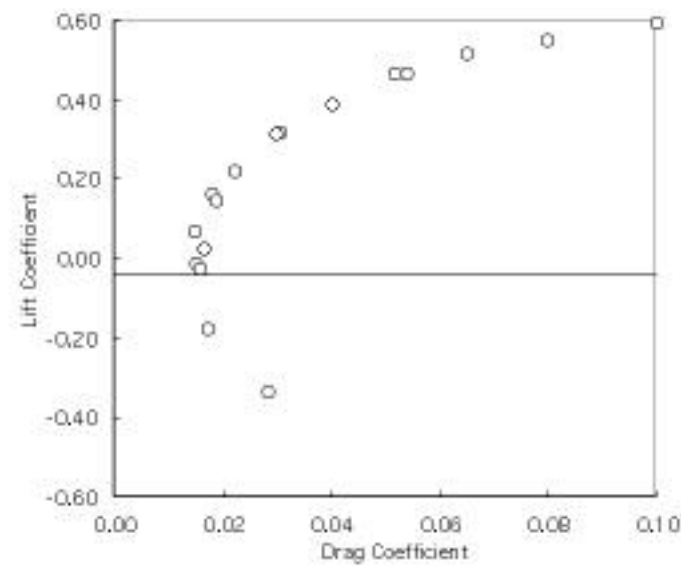

Figure 7.- Drag polar for alpha variation, $M=0.77$ and $\mathrm{q}=141.5 \mathrm{psf}$.

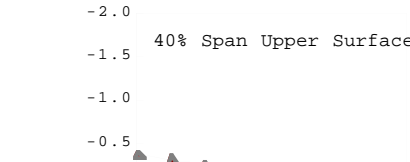

Figure 8.- Variation of upper- and lower-surface mean pressures with alpha, $\mathrm{M}=0.77$ and $\mathrm{q}=141.5 \mathrm{psf}$. 


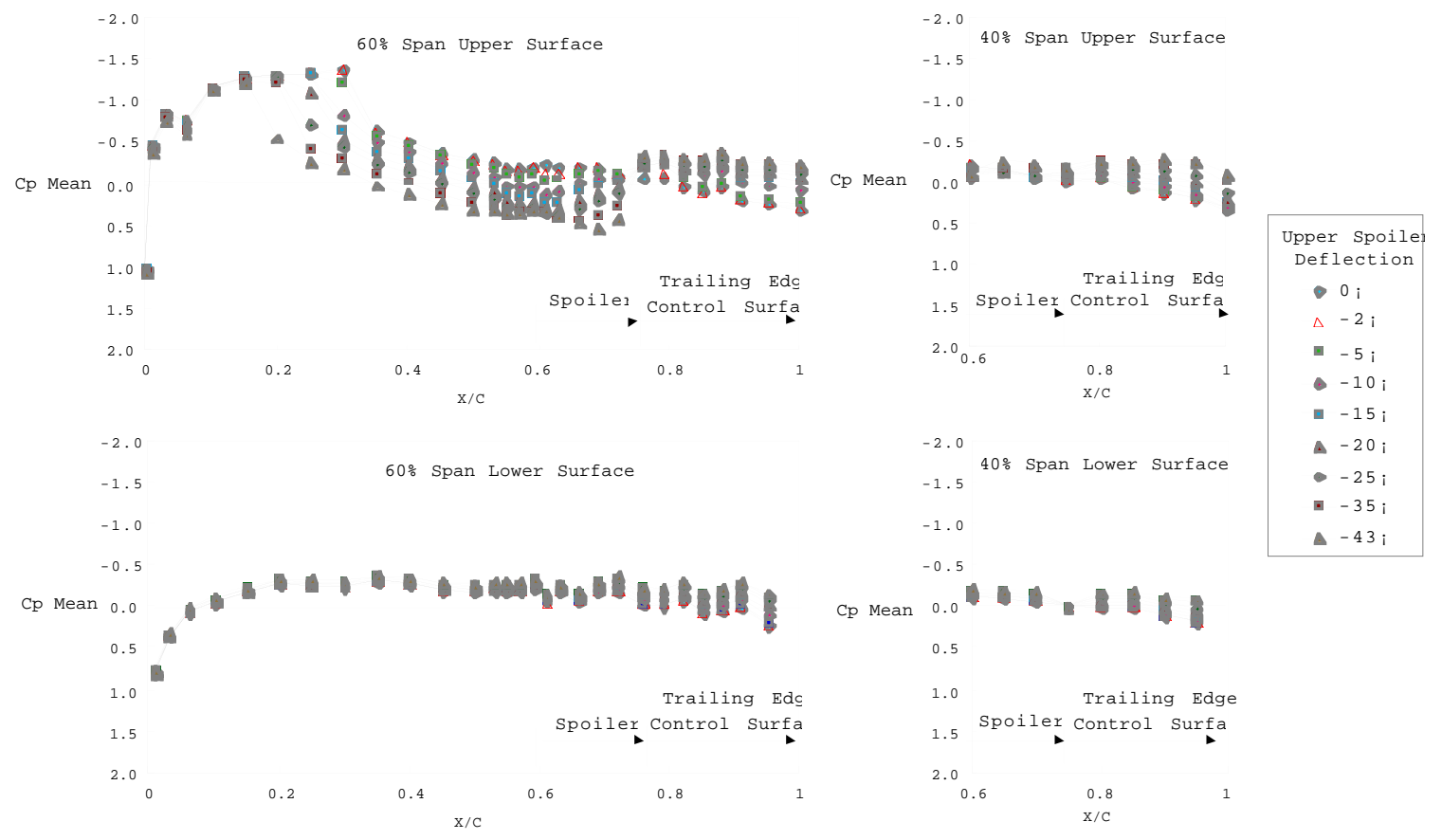

Figure 9.- Variation of upper- and lower-surface mean pressures with upper spoiler control surface deflection, $\alpha=5^{\circ}$, $\mathrm{M}=0.77$, and $\mathrm{q}=152.1 \mathrm{psf}$.

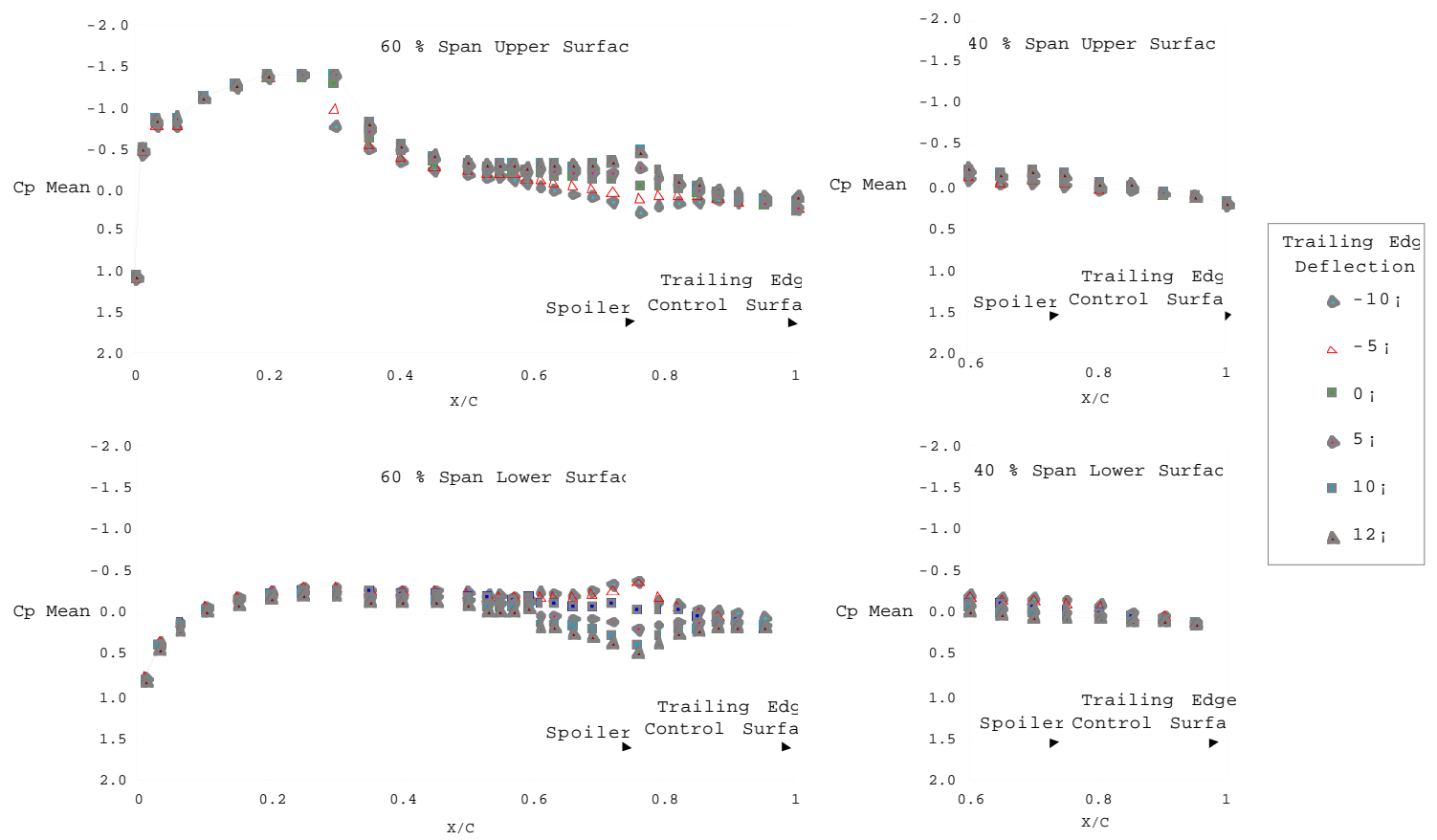

Figure 10.-Variation of upper- and lower-surface mean pressures with trailing edge control surface deflection, $\alpha=5^{\circ}$, $\mathrm{M}=0.77$, and $\mathrm{q}=145.7 \mathrm{psf}$. 


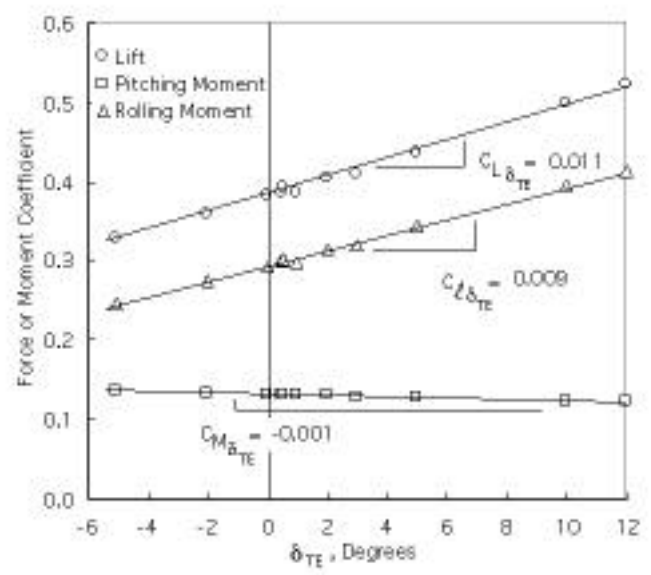

Figure 11.- Force and moment coefficients as a function of trailing edge control surface deflection, $\alpha=5^{\circ}$, $\mathrm{M}=0.77$, and $\mathrm{q}=145.7 \mathrm{psf}$.

The unsteady rigid data are summarized in Table 4 . These data are organized by control surface used, excitation type, and Mach number. Most of this data consist of responses to dwells and linear sign sweeps; however, several PPN excitations were also employed for comparison purposes. Since the PPN excitation does not dwell on any one frequency, higher signal to noise ratios can be obtained when testing near instabilities, but in general the responses are not as clean and require more averages than linear sine sweeps to clean up the results. The dwell data are most easily examined by viewing the results in the frequency domain at the excitation frequency. Figure

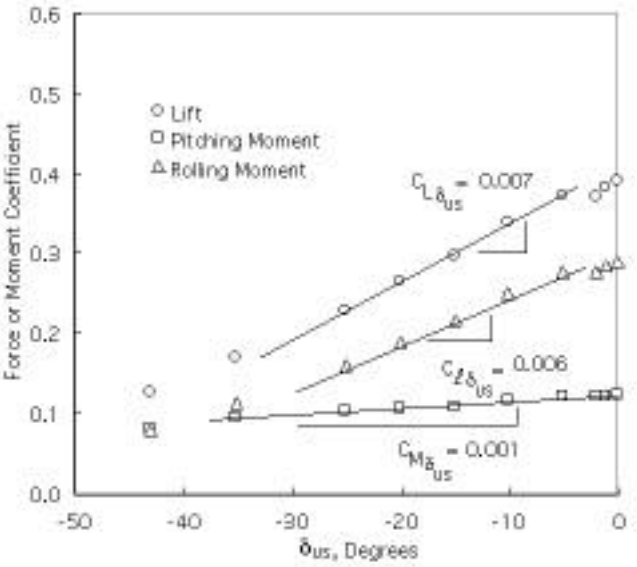

Figure 12.- Force and moment coefficients as a function of upper spoiler control surface deflection, $\alpha=5^{\circ}$, $\mathrm{M}=0.77$, and $\mathrm{q}=152.1 \mathrm{psf}$.

13 shows the magnitude and phase of the pressure coefficients for a $5 \mathrm{~Hz}$ oscillation of the trailing edge control surface. There are two peaks in the magnitude plot. One occurs at approximately the $30 \%$ chord station where the motion of the trailing edge control surface is moving the upper surface shock wave back and forth over the pressure transducer. The other peak occurs on the control surface nearest the hinge line. Although not shown, linear sine sweep and PPN time histories allow for the calculation of frequency response functions for any or all of the pressure transducers and loads across a frequency range of interest.

Table 4.- Unsteady rigid data.

\begin{tabular}{|c|c|c|c|c|c|c|c|}
\hline \multirow[b]{2}{*}{$\mathrm{M}$} & \multirow[b]{2}{*}{$q(p s f)$} & \multirow{2}{*}{$\begin{array}{l}\text { Control } \\
\text { Surface }\end{array}$} & \multirow[b]{2}{*}{ Excitation Description } & \multirow{2}{*}{$\begin{array}{c}\text { Alpha } \\
\text { (Degrees) }\end{array}$} & \multicolumn{3}{|c|}{ Biases (Degrees) } \\
\hline & & & & & TE & US & LS \\
\hline 0.65 & 745 & TE & Dwell: 2,5,10 Hz. @ 1,2,4Amp. & 0,4 & 0 & 0 & 0 \\
\hline 0.77 & $140-152$ & TE & Dwell: 2,5,10 Hz. @ 1,2,4Amp. & $0,2,4$ & 0,5 & $0,-5,-10,-20$ & 0 \\
\hline 0.82 & 175 & TE & Dwell: 2,5,10 Hz. @ 1,2,4 Amp. & 0,4 & 0 & 0 & 0 \\
\hline 0.90 & 138,175 & TE & Dwell: 2,5,10 Hz. @ 1,2,4Amp. & $0,0.5$ & 0 & 0 & 0 \\
\hline 0.82 & 175 & TE & LinSS: 0.5 to $12 \mathrm{~Hz}$. @1,2,4 ${ }^{\circ} \mathrm{Amp}$. & $0,0.5$ & 0 & 0 & 0 \\
\hline 0.77 & $144-150$ & TE & LinSS: 0.5 to $12 \mathrm{~Hz}$. @ $1,3,4^{\circ} \mathrm{Amp}$. & 0 & 0,5 & $0,-5,-10,-20$ & 0 \\
\hline 0.77 & $144-150$ & TE & LinSS: 0.5 to $12 \mathrm{~Hz}$. @1,3,4 $4^{\circ} \mathrm{Amp}$. & $0,2,4,5,6$ & 0 & $0,-20$ & 0 \\
\hline 0.65 & 145 & TE & LinsS: 0.5 to $12 \mathrm{~Hz}$. @ $4^{\circ} \mathrm{Amp}$. & 0,4 & 0 & 0 & 0 \\
\hline 0.77 & $143-150$ & TE & PPN: 0.5 to $12 \mathrm{~Hz}$. @ 1,3,4 Amp. & 0 & 0,5 & $0,-5,-10,-20$ & 0 \\
\hline 0.77 & $143-150$ & TE & PPN: 0.5 to $12 \mathrm{~Hz}$. @ 1,3,4 Amp. & $2,4,5$ & 0 & $0,-20$ & 0 \\
\hline 0.65 & 145 & US & Dwell: 2,5,10 Hz. @ 1,2,4Amp. & 0,4 & 0 & -10 & 0 \\
\hline 0.77 & $148-153$ & US & Dwell: 2,5,10 Hz. @ 1,2,4 Amp. & $0,2,5$ & 0 & $-5,-10,-20$ & 0 \\
\hline 0.82 & $175-177$ & US & Dwell: 2,5,10 Hz. @ 1,2,4Amp. & 0,4 & 0 & $-10,-20$ & 0 \\
\hline 0.90 & 138 & US & Dwell: 2,5,10 Hz. @ 1,2,4 Amp. & $0,0.5$ & 0 & -2 & 0 \\
\hline 0.65 & 145 & US & LinSS: 0.5 to $12 \mathrm{~Hz}$. @2,10 Amp. & 0,4 & 0 & -10 & 0 \\
\hline 0.77 & $148-153$ & US & LinSS: 0.5 to $12 \mathrm{~Hz}$. @2,10 Amp. & $0,2,5$ & 0 & $0,-10,-20$ & 0 \\
\hline 0.82 & $175-177$ & US & LinSS: 0.5 to $12 \mathrm{~Hz}$. @2,10 Amp. & 0,4 & 0 & $-10,-20$ & 0 \\
\hline 0.90 & 138 & US & LinSS: 0.5 to $12 \mathrm{~Hz}$. @2,10 Amp. & $0,0.5$ & 0 & -2 & 0 \\
\hline 0.77 & $149-178$ & LS & Dwell: 2,5,10 Hz. @ 1,2,4 Amp. & $0,2,4,5$ & 0 & 0 & $5,10,20$ \\
\hline
\end{tabular}




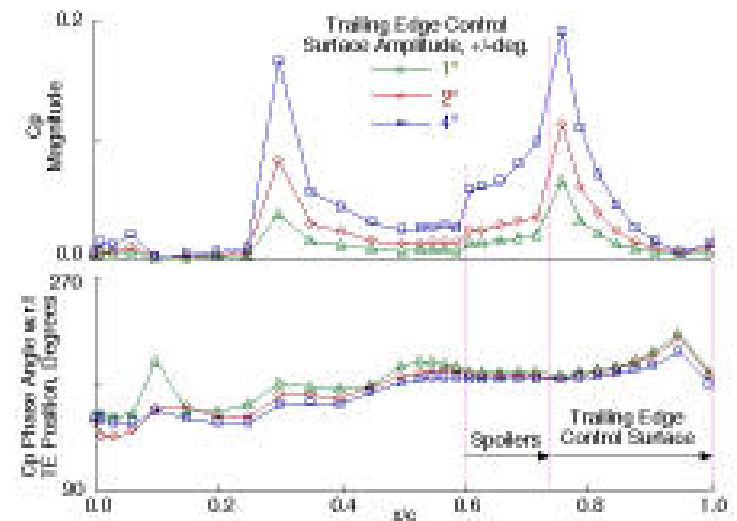

Figure 13.- Unsteady upper-surface pressures at $60 \%$ span station due to trailing edge control surface excitation at $5 \mathrm{~Hz}$., $\alpha=5^{\circ}, \mathrm{M}=0.77$, and $\mathrm{q}=153$ psf.

\section{Flexible Mount}

Three types of instabilities were encountered with the BACT/PAPA system. One was a classical flutter instability where the two primary vibratory modes coalesce. The other instabilities were a plunge instability and a stall instability. The points where instabilities occurred are shown in Figure 14. The boundaries where these instabilities occurred are similar to the ones encountered in the previous NACA 0012 Benchmark model test described in reference 7 . Time history data were acquired at these points and at some of these points, magnitude and phase of pressures were also calculated at the frequency of the instability.

The classical flutter boundary for the BACT model is represented by the square symbols in Figure 14. The open-loop model is stable below this boundary and unstable above. This boundary was obtained with zero bias on the control surfaces and an angle of attack large enough to create lift approximately equal to weight of the model, typically a value near 2 degrees was used. There is a transonic dip near

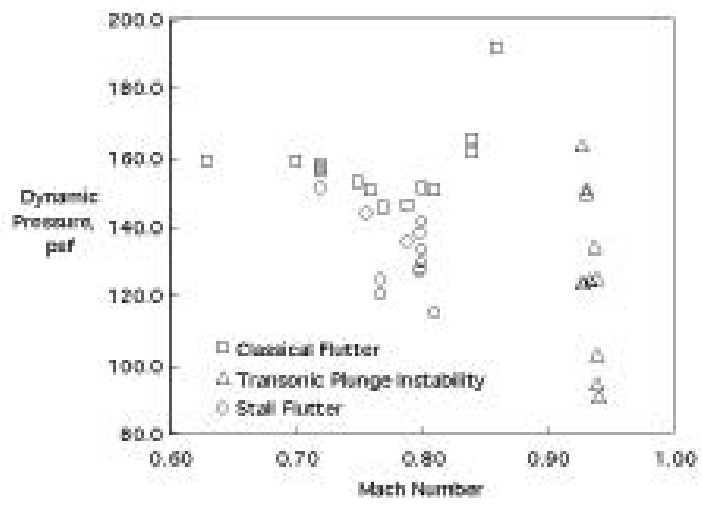

Figure 14.- BACT instabilities.
$\mathrm{M}=0.77$ followed by a sharp upward turn of the boundary near $\mathrm{M}=0.8$. For the $\mathrm{M}=0.63$ and $\mathrm{q}=158$ psf flutter point, magnitude and phase at the flutter frequency of $4.3 \mathrm{~Hz}$ are shown in Figure 15. The zero magnitude data points in Figure 15 correspond to transducers that were no longer functioning. Prior to each wind-tunnel run, 1 psi checks were performed to evaluate the transducer's calibration and functionality. This provides with certainty the accuracy of each transducer for steady data; however, a transducer can pass this test and still be inaccurate for unsteady data. An example of this is the transducer on the trailing edge control surface that doesn't fit the trend. This transducer probably has a partially blocked reference tube rendering it unreliable for unsteady data.

Occurrences of a plunge instability are indicated by the triangular symbols in Figure 14. This instability occurs in a narrow transonic Mach number range around 0.92 and, as implied, consists primarily of the plunge mode at a frequency around $3.5 \mathrm{~Hz}$. Since this instability is caused by the fore and aft motion of symmetric shocks on the upper and lower surface of the wing, it is very sensitive to any biases and does not occur with nonzero control surface bias or nonzero alpha.

Occurrences of stall flutter are indicated by the circular symbols in Figure 14. This instability is caused by wing stall occurring during a portion of the pitch oscillation cycle. The primary mode in this instability is the pitch mode at a frequency around 5 $\mathrm{Hz}$. This instability could be encountered at most tunnel conditions where high angles of attack could be attained without exceeding the load limits for the

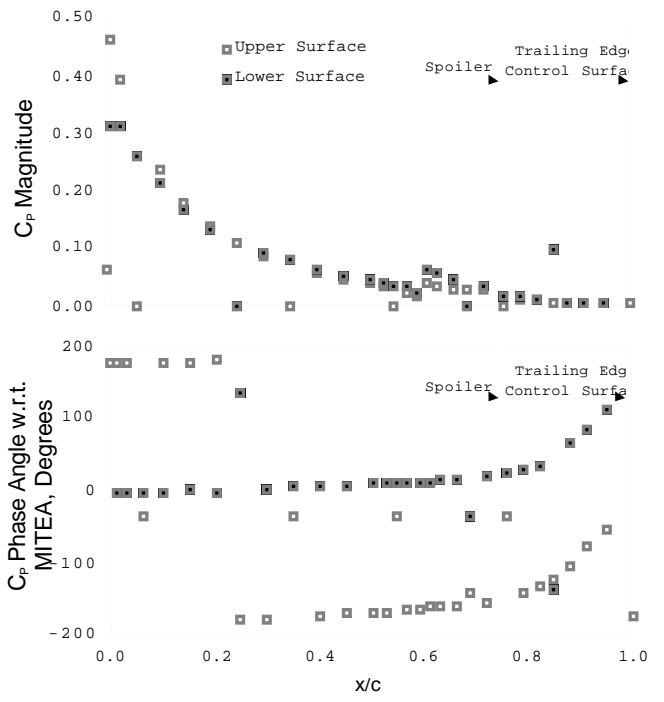

Figure 15.- Unsteady pressures at $60 \%$ span acquired during flutter, $\mathrm{M}=0.63$ and $\mathrm{q}=158 \mathrm{psf}$. 
Table 5.- Unsteady PAPA data.

\begin{tabular}{|c|c|c|c|c|c|c|c|}
\hline \multirow[b]{2}{*}{ M } & \multirow[b]{2}{*}{$q(p s f)$} & \multirow{2}{*}{$\begin{array}{l}\text { Control } \\
\text { Surface }\end{array}$} & \multirow[b]{2}{*}{ Excitation Description } & \multirow{2}{*}{$\begin{array}{l}\text { Alpha } \\
\text { (Deg.) }\end{array}$} & \multicolumn{2}{|r|}{ Biases (Degrees) } & \multirow[b]{2}{*}{ LS } \\
\hline & & & & & TE & US & \\
\hline $0.5,0.65,0.7,0.75,0.77,0.8,0.94$ & $101-140$ & TE & Dwell: $3.2-5 \mathrm{~Hz}$. & 0,2 & 0 & 0 & 0 \\
\hline $0.5,0.65,0.70,0.75,0.77,0.8,0.88$ & $101-130$ & TE & LinSS: $2-8$ \& 0.5-12 Hz. & 2 & 0 & 0 & 0 \\
\hline $0.5,0.65,0.7,0.75,0.77,0.8,0.84,0.88,0.94$ & $101-135$ & TE & PPN: 2-8 \& 0.5-12 Hz. & 0,2 & 0 & $0,-5,-40$ & $0,5,40$ \\
\hline $.65, .85$ & 74,114 & TE & LinSS: $0.5-12 \mathrm{~Hz}$ & 1.7 & 0 & $0,-5,-10,-15,-20$ & $0,5,10,15,20$ \\
\hline $0.5,0.65,0.7,0.75,0.77,0.8,0.88$ & $116-130$ & US & Dwell: $2.0-10 \mathrm{~Hz}$. & 2 & 0 & $0,-5,-10$ & 0 \\
\hline $0.5,0.65,0.70,0.75,0.77,0.80,0.88$ & $116-130$ & US & LinSS: $0.5-12 \mathrm{~Hz}$ & 2 & 0 & $0,-3,-5,-10$ & 0 \\
\hline $0.5,0.65,0.7,0.75,0.77,0.8,0.88$ & $115-133$ & US & PPN: 2-8 \& 0.5-12 Hz. & 2 & 0 & $0,-3,-5,-10$ & 0 \\
\hline $.65, .84$ & 115,135 & US & PPN: 2-8 \& 0.5-12 Hz. & 0,2 & 0 & $0,-10$ & 0,10 \\
\hline $0.65,0.7,0.75,0.77,0.8,0.88,0.92$ & $101-130$ & US+LS & Dwell: 3-5 Hz. & 0,2 & 0 & $0,-3,-5,-10$ & $0,3,5,10$ \\
\hline $0.5,0.65,0.70,0.75,0.77,0.80,0.88$ & $103-130$ & US+LS & LinSS: $2-8 \& 0.5-12 \mathrm{~Hz}$ & 2 & 0 & $0,-3,-5,-10$ & $0,3,5,10$ \\
\hline $0.5,0.65,0.7,0.75,0.8,0.84,0.880 .93$ & $101-130$ & US+LS & PPN: 2-8 \& 0.5-12 Hz. & 0,2 & 0 & $0,-2,-3,-10,-20,-40$ & $0,2,3,10,20,40$ \\
\hline $.65, .85$ & 74,114 & US+LS & LinSS: $0.5-12 \mathrm{~Hz}$. & 1.7 & 0 & -10 & 10 \\
\hline 0.92 & 124 & US-LS & Dwell: $3 \mathrm{~Hz}$. & 0 & 0 & -2 & 2 \\
\hline 0.65 & 115 & US-LS & LinSS: $0.5-12 \mathrm{~Hz}$. & 2 & 0 & -10 & 10 \\
\hline 0.65 & 113 & LS & Dwell: 3.44 \& 4.56 Hz. & 2 & 0 & -2 & 2 \\
\hline 0.65 & 113 & LS & PPN: 0.5-12 Hz. & 2 & 0 & 0 & 10 \\
\hline
\end{tabular}

PAPA mount. Generally stall flutter was encountered at mean angles exceeding 4 degrees.

Below the flutter boundary, control surface inputs were used to excite the BACT model so that transfer functions could be calculated and compared with results of aeroservoelastic codes. The types of excitations along with the corresponding tunnel conditions and biases are summarized in Table 5. An example transfer function calculation is shown in Figure 16. Here, both spoilers were biased $10^{\circ}$ into the airstream, and their input was a linear sine sweep. Note that for this condition, the two primary modes of motion, pitch and plunge, still exist as distinct modes as indicated by the separate peaks in the magnitude plot. Reference 8 made extensive use of this data to compare with aeroservoelastic models of the BACT plant.
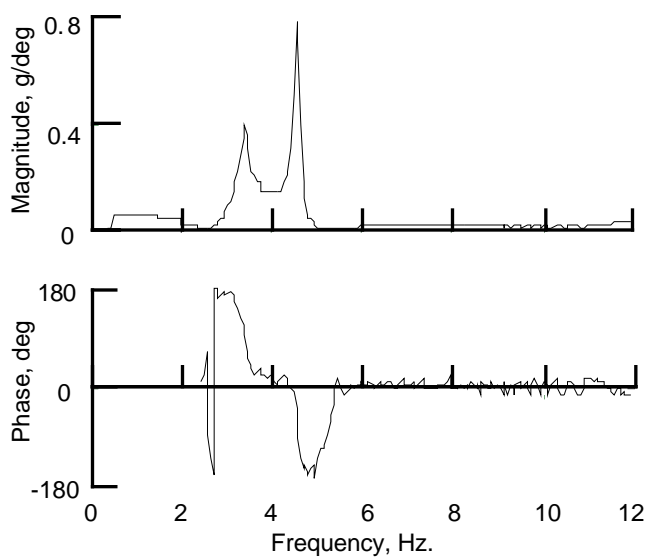

Figure 16.- Acceleration transfer function due to upper and lower spoiler position, $\mathrm{M}=0.65$ and $\mathrm{q}=114 \mathrm{psf}$.

\section{CONCLUDING REMARKS}

The results from three Benchmark Active Controls Technology (BACT) tests are available for use to better understand the classical and nonlinear flutter mechanisms encountered in transonic flows, to evaluate control-surface and spoiler effectiveness, to study controllability and linearity issues, and to assess, expand, and validate modeling and design tools for applying active control concepts to alleviate aeroelastic phenomena.

During the three wind-tunnel tests in the TDT, an extensive database of over 3000 data sets was obtained for the BACT model. Transonic, subsonic, attached, and separated flow conditions were explored. This experimental database, which is available to correlate with analytical predictions, provides unique transonic and subsonic measurements for both the validation of CFD codes and control law design. Aerodynamic loads and wing pressures were acquired for various combinations of trailing edge control surface deflection, spoiler deflection, and wing angle of attack. The stability boundaries for classical flutter and for other nonlinear aeroelastic instabilities in transonic flow were also explored and measured. Measurements were acquired to evaluate the dynamic response characteristics due to various combinations of excitation and static deployment of the three control surfaces. An extensive database of transient and frequency response data were also acquired for subsonic through transonic Mach numbers over a wide range of dynamic pressures. The combination of force testing and pressure measurements will permit detailed diagnostics and the exploration of limitations for computer program applications. 


\section{REFERENCES}

1. Rivera, Jose A., Jr.; Dansberry, Bryan E.; Farmer, Moses G.; Eckstrom, Clinton V.; Seidel, David A.; Bennett, Robert M.: Experimental Flutter Results With Steady and Unsteady Pressure Measurements of a Rigid Wing on a Flexible Mount System. AIAA 91-1010, April 1991.

2. Durham, Michael H.; Keller, Donald F.; Bennett, Robert M.; Wieseman, Carol D.: A Status Report on a Model for Benchmark Active Controls Testing. AIAA 91-1011, April 1991. Also published as NASA TM 107582.

3. Waszak, Marty R. and Fung, James; Parameter Identification and Analysis of Actuators for the BACT Wind-Tunnel Model. AIAA 96-3362, July 1996.

4. Farmer, M.G.: A Two-Degree-of-Freedom Flutter Mount System with Low Damping for Testing Rigid Wings at Different Angles of Attack. NASA TM 83302, 1982.
5. Aeroelasticity Branch Staff: Langley Working Paper - The Langley Transonic Dynamics Tunnel. LWP-799, September 23, 1969.

6. Pototzky, Anthony S.; Wieseman, Carol D.; Hoadley, Sheri T.; and Mukhopadhyay, Vivek: On-Line Performance Evaluation Of MultiLoop Digital Control Systems. Journal of Guidance Control and Dynamics, Vol. 15, No. 4, 1992, pp 878-884.

7. Rivera, Jose A., Jr.; Dansberry, Bryan E.; Bennett, Robert M.; Durham, Michael.H.; and Silva, Waltar A.: NACA 0012 Benchmark Model Experimental Flutter Results With Unsteady Pressure Distributions. NASA TM 107581, March 1992.

8. Waszak, Martin R.: Modeling the Benchmark Active Controls Technology Wind-Tunnel Model for Application to Flutter Suppression. AIAA 96-3437, July 1996. 